\title{
Association between Thyroiditis and Multifocality in Papillary Thyroid Carcinoma
}

\author{
Rogério Aparecido Dedivitis ${ }^{1,2(0)}$ Leandro Luongo de Matos ${ }^{1,3}$ Felipe Guilherme Silva Souza $4(0$ \\ Jose Luis Bogado Ortiz ${ }^{4}$
}

1 Department of Surgery, Faculdade de Medicina, Universidade de São Paulo, São Paulo, São Paulo, Brazil

2 Department of Head and Neck Surgery, Hospital das Clínicas, Faculdade de Medicina, Universidade de São Paulo, São Paulo, São Paulo, Brazil

${ }^{3}$ Department of Head and Neck Surgery, Instituto do Câncer do Estado de São Paulo (Icesp), São Paulo, São Paulo, Brazil

${ }^{4}$ Department of Head and Neck Surgery, Hospital Ana Costa, Santos, São Paulo, Brazil

Int Arch Otorhinolaryngol 2021;25(2):e219-e223.
Address for correspondence Rogério Aparecido Dedivitis, Departmento de Cirurgia, Faculdade de Medicina, Universidade de São Paulo, Av. Conselheiro Nébias, $444,16^{\circ}$ Andar, 11045-000, Santos, SP, Brazil (e-mail: dedivitis.hns@uol.com.br).

\begin{abstract}
Keywords

- thyroiditis

- thyroid cancer

- papillary thyroid carcinoma

Introduction Hashimoto thyroiditis (HT) shares many characteristics with papillary thyroid carcinoma (PTC), and some studies show that, when associated, PTC is diagnosed mostly with smaller lesions and multifocal pattern.

Objective To evaluate the relationship between HT and PTC.

Methods A retrospective study of 155 patients who underwent total thyroidectomy from 2009 to 2015. Demographical, clinical and ultrasonographical data, as well as anatomopathological findings were evaluated.

Results There were signs of thyroidits in 35 patients, and 114 patients had a unifocal disease. There was no statistical significance between the variables studied and thyroiditis. However, when compared with the occurrence of unifocal or multifocal lesions, there was statistical significance regarding age $(p=0.038)$ and mass $(p=0.031)$. There was no direct relationship between thyroiditis and multifocality $(p=0.325)$ nor between thyroiditis and cervical extension of the disease $(p=0.300 \mathrm{e}$ $p=0.434)$.

Conclusion There was no relationship between thyroiditis and multifocality in cases of PTC.
\end{abstract}

\section{Introduction}

Hashimoto thyroiditis (HT) was first described in 1912 by the Japanese surgeon Hakaru Hashimoto, in Berlin, Germany. ${ }^{1}$ It is the most common disease in the thyroid gland, and it occurs mainly in women. ${ }^{2}$ It is an inflammatory autoimmune disease with diffuse infiltration of the gland by lymphocytes,

leading to fibrosis and atrophy, and is the most common cause of hypothyroidism. ${ }^{3-5}$ Papillary thyroid carcinoma (PTC) is the most common thyroid cancer, responsible for $\sim 70 \%$ to $80 \%$ of cases of this tumor.

The first causal association between both conditions was proposed in 1955 by Dailey et al. ${ }^{6}$ However, some received

October 13, 2019

accepted

March 12, 2020

published online

June 23, 2020
DOI https://doi.org/ 10.1055/s-0040-1710307. ISSN 1809-9777.

\footnotetext{
(c) 2020. Fundação Otorrinolaringologia. All rights reserved.

This is an open access article published by Thieme under the terms of the Creative Commons Attribution-NonDerivative-NonCommercial-License, permitting copying and reproduction so long as the original work is given appropriate credit. Contents may not be used for commercial purposes, or adapted, remixed, transformed or built upon. (https://creativecommons.org/ licenses/by-nc-nd/4.0/)

Thieme Revinter Publicações Ltda., Rua do Matoso 170, Rio de Janeiro, RJ, CEP 20270-135, Brazil
} 
controversy still remains. Some papers suggest a strong relationship between them, ${ }^{7-9}$ whereas others do not. ${ }^{1,10,11}$

Hashimoto thyroiditis shares many characteristics with PTC, such as similar morphology, immunohistochemical pattern, and molecular profile, suggesting that it could be a predisposing factor for PTC. ${ }^{10}$ Thus, some papers show that, in patients with HT, there is an increase of 30\% in cases of PTC. When associated with HT, PTC is diagnosed mostly in young women, with smaller lesions, in an early and multifocal pattern, and with better prognosis. $3,5,7,8,12$

The objective of the present study was to evaluate the relationship between these diseases.

\section{Methods}

The present study was approved by the Ethics and Research Committe of the institution in which it was performed under number 83977318.4.0000.5509.

It is a retrospective study to evaluate the medical records of patients treated in a tertiary reference facility. In total, 155 patients treated between 2009 and 2015 were evaluated. They underwent total thyroidectomy, with or without neck dissection and radioiodine therapy, according to the protocol of the institution.

Demographical data (gender and age), clinical and ultrasonographic data, as well as anatomopathological findings (presence of chronic thyroiditis, size and multicentricity of the lesions and staging of the neck) were evaluated. All histopathological data was reviewed by the same pathologist. Based on the histopathological findings, the possible risk factors for multicentricity, including the presence of chronic thyroidits, were evaluated.

Frequency distribution was used to describe the categorical variables, (number of cases and percentage) the central measurement tendencies (average and median) and dispersion measurements. The Student $t$-test was used to check the association between the numerical variables, and the Fisher exact test was employed to compare the categorical variables. A significance level of $5 \%$ was used for all statistical tests.

\section{Results}

In total, 155 files of patients were evaluated after the anatomopathological analysis of the surgical specimens: 120

Table 1 Patient distribution $(n=155)$

\begin{tabular}{|l|l|l|l|}
\hline Aspect & $\begin{array}{l}\text { With } \\
\text { thyroiditis } \\
(\boldsymbol{n}=35)\end{array}$ & $\begin{array}{l}\text { Without } \\
\text { thyroiditis } \\
(\boldsymbol{n}=120)\end{array}$ & Total \\
\hline Men & $6(17.1 \%)$ & $13(10.9 \%)$ & 19 \\
\hline Women & $29(82.9 \%)$ & $107(89.1 \%)$ & 136 \\
\hline Unifocal & $28(80 \%)$ & $86(71.6 \%)$ & 114 \\
\hline Multifocal & $7(20 \%)$ & $36(28.4 \%)$ & 41 \\
\hline N0 & $34(97.1 \%)$ & $109(90.8 \%)$ & 143 \\
\hline N1a & $1(2.9 \%)$ & $8(6.6 \%)$ & 9 \\
\hline N1b & 0 & $3(2.6 \%)$ & 3 \\
\hline
\end{tabular}

Table 2 Average characteristics of the patients according to the presence of thyroiditis

\begin{tabular}{|l|l|l|l|}
\hline & $\begin{array}{l}\text { Without } \\
\text { thyroiditis }\end{array}$ & $\begin{array}{l}\text { With } \\
\text { thyroiditis }\end{array}$ & -value \\
\hline Age (years) & 50.37 & 52.71 & 0.434 \\
\hline Mass (grams) & 26.91 & 25.20 & 0.795 \\
\hline $\begin{array}{l}\text { Measurement } \\
\text { of the higher } \\
\text { focus (mm) }\end{array}$ & 12.77 & 12.26 & 0.737 \\
\hline
\end{tabular}

showed no signs of thyroiditis, 114 showed unifocal disease, and 143 didn't developed regional metastasis (- Table 1).

After the evaluation and comparison of the results, the main variables were age, size of the largest focus and glandular mass. There was no statistical significance when these variables were related to the presence of thyroiditis (-Table 2). However, when compared with the occurrence of unifocal or multifocal lesions, there was statistical significance for age $(p=0.038)$ and mass $(p=0.031)$ ( - Table 3$)$. Nevertheless, the tests did not show the same results for multifocality and uni/bilaterality (-Tables 4).

There was no direct relationship between thyroiditis and multifocality $(p=0.325)$ nor between thyroiditis and cervical extension of the disease $(p=0.300$ and $p=0.434)$ (-Table 5).

\section{Discussion}

Some controversy in the literature still remains about the relationship between HT and PTC. Some papers ${ }^{3-5,12}$ suggest a strong positive relationship between them, as well as a cause and effect relation in which the inflammatory process

Table 3 Average characteristics of the patients according to multifocality

\begin{tabular}{|l|l|l|l|}
\hline & $\begin{array}{l}\text { Unilateral } \\
\text { multifocal } \\
\text { lesions }\end{array}$ & $\begin{array}{l}\text { Bilateral } \\
\text { lesions }\end{array}$ & $p$-value \\
\hline Age (years) & 48 & 46 & 0.707 \\
\hline Mass (grams) & 28.16 & 19.37 & 0.53 \\
\hline $\begin{array}{l}\text { Measurement } \\
\text { of the higher } \\
\text { focus (mm) }\end{array}$ & 15 & 16.48 & 0.99 \\
\hline
\end{tabular}

Table 4 Comparison between unifocal and multifocal lesions

\begin{tabular}{|l|l|l|l|}
\hline & $\begin{array}{l}\text { Unifocal } \\
\text { lesion }\end{array}$ & $\begin{array}{l}\text { Multifocal } \\
\text { lesions }\end{array}$ & $p$-value \\
\hline Age (years) & 52.45 & 46.59 & 0.038 \\
\hline Mass (grams) & 28.17 & 21.95 & 0.031 \\
\hline $\begin{array}{l}\text { Measurement } \\
\text { of the higher } \\
\text { focus (mm) }\end{array}$ & 11.43 & 16.05 & 0.104 \\
\hline
\end{tabular}


Table 5 Relationship between thyroiditis and multifocality and neck staging

\begin{tabular}{|l|l|l|l|l|}
\hline & $\begin{array}{l}\text { With } \\
\text { thyroiditis } \\
(\boldsymbol{n}=35)\end{array}$ & $\begin{array}{l}\text { Without } \\
\text { thyroiditis } \\
(\boldsymbol{n}=120)\end{array}$ & Total & $p$-value \\
\hline Unifocal & $28(80 \%)$ & $86(71.7 \%)$ & $114(100 \%)$ & 0.325 \\
\hline Multifocal & $7(20 \%)$ & $34(28.3 \%)$ & $41(100 \%)$ & 0.325 \\
\hline N0 & 34 & $\begin{array}{l}109 \\
(90.8 \%)\end{array}$ & $\begin{array}{l}143 \\
(92.3 \%)\end{array}$ & 0.300 \\
\hline N1a & $1(2.9 \%)$ & $8(6.7 \%)$ & $9(5.8 \%)$ & 0.434 \\
\hline N1b & 0 & $3(2.5 \%)$ & $3(1.9 \%)$ & 0.434 \\
\hline N+ & $1(2.9 \%)$ & $11(9.2 \%)$ & $12(7.7 \%)$ & 0.300 \\
\hline
\end{tabular}

from the thyroiditis could lead to malignant transformation. This chronic inflammatory response could induce several damages in the DNA through the development of free radicals, resulting in mutations that could promote the transformation to PTC. On the other hand, other studies ${ }^{1,2}$ suggest this is just an accidental finding in the samples. As a result, it is difficult to determine if $\mathrm{HT}$ is a predisposing factor for PTC or if it is only a response of the organism to the development of PTC. ${ }^{12}$

Epidemiological and histological data show that PTC often occurs in the context of thyroiditis, and is often infiltrated by inflammatory-immune cells. In spite of the fact that an elevated level of serum thyroglobulin antibody (TgAb) is an independent predictor for PTC, the level of serum thyroid peroxidase antibody (TPOAb) was not present in the univariate and multivariate analyses. Some studies failed to identify this relationship probably due to the high diversity of the $\operatorname{TgAb}$ assay. ${ }^{13}$ The mechanism of such an association is unknown. It is possible that $\mathrm{TgAb}$ has a tumorigenic effect or is strongly associated with a specific tumorigenic inflammatory response. Changed processing or mutation in the molecular structure of thyroglobulin can increase its antigenicity. On the other hand, the TPOAb does not present an apparent relationship with PTC. Maybe the tumorigenic effect of thyroid inflammation can be avoided by its cytotoxic effect. ${ }^{14}$

The main indications for thyroidectomy used to be a lack of response to the pharmacological therapy for hyperthyroidism, compressive symptoms, suspicious or inconclusive cytology and history, or a physical examination that demanded investigation/treatment for cancer (vocal-fold paralysis, pain or increase in the size of cervical lymph nodes). ${ }^{15,16}$ However, most patients with thyroiditis do not need the surgical procedure.

In samples obtained from fine needle aspiration (FNA), an important difference in the prevalence and hazard ratio was found between PTC when compared with specimens obtained after thyroidectomy. The prevalence of PTC in specimens after FNA biopsy in patients with thyroiditis was of $1.2 \%$, whereas in surgical specimens it was of $27.56 \%$. This variability could be the result of different methods when obtaining samples and the heterogeneity of the population in distinct studies. ${ }^{12}$
The use of FNA for the diagnosis of PTC in patients with thyroiditis shows a sensitivity of $90 \%$ and negative predictive values of $96 \%{ }^{17,18}$ However, the diagnostic accuracy is diminished in follicular lesions and Hürthle-cell neoplasm, which could lead to false-positives and negatives in some cases. ${ }^{17-21}$ Despite some disadvantages, FNA is indicated as an initial method of investigation of PTC before other more invasive procedures are performed.

An important association between thyroiditis and PTC was found, mainly when associated with multifocality, early tumors and small lesions, ${ }^{12}$ which corroborates the hypothesis that the immune response plays a fundamental role in the development of malignant thyroid neoplasms. Nevertheless, our study showed no statistical significance for these variables. In 155 specimens analyzed, 22.58\% showed thyroiditis associated with PTC, a percentage lower than that of some findings from the literature, which report percentages of $\sim 37.2 \%{ }^{22,23}$ The main hypothesis for that association would be a result of the changes in the glandular stroma. ${ }^{24,25}$ The articles are controversial, suggesting that the association between HT and PTC would be related to a better prognosis with a smaller recurrence. ${ }^{26}$ Meanwhile, other studies show that this association will not change the aggressiveness of the disease. $^{27}$ A metanalysis ${ }^{7}$ gathered 38 studies including 10,648 PTC patients. Histologically-confirmed thyroiditis was identified in 2,471 (23.2\%) cases of PTC, which was significantly related to multifocal diseases (odds ratio $[\mathrm{OR}]=1.5 ; p=0.010)$. A total of 12 studies addressed the frequencies of thyroiditis in uni- and multifocal cancers, including 1,378 cases with multifocal PTC and 2,549 cases with unifocal PTC. Thyroiditis was more frequently observed in multifocal PTC than in the unifocal disease; however, a significant statistical heterogeneity was verified in the studies. $^{7}$

Our study showed positive and statistical significance between multifocality, age and glandular mass. Some articles ${ }^{28-30}$ in the literature remain controversial on this point. In spite of the fact that the age of the patients is similar in the studies, some ${ }^{28,29}$ point out that there is no relationship or difference in age and glandular mass with unifocal or multifocal lesions, whereas others ${ }^{30}$ show a positive relationship between these variables. It is possible that more studies, with a larger number of patients enrolled, would be necessary in order to reach a definitive conclusion.

We did not find statistical significance in the analysis of cervical extension (neck metastasis) when compared with multifocality and thyroiditis when associated, just like many studies. ${ }^{31-33}$ However, other studies show that multifocality is an independent risk factor for the occurrence of neck metastasis, mainly in the central neck ${ }^{34-41}$ and regarding young male patients. ${ }^{29}$

\section{Conclusion}

There was no relationship between thyroiditis and the occurrence of multifocality in cases of PTC. However, we found statistical significance between multifocality, glandular mass and the age of the patients in the study. 


\section{Conflict of Interests}

The authors have no conflict of interests to declare.

\section{References}

1 Mazokopakis EE, Tzortzinis AA, Dalieraki-Ott EI, et al. Coexistence of Hashimoto's thyroiditis with papillary thyroid carcinoma. A retrospective study. Hormones (Athens) 2010;9 (04):312-317

2 Jankovic B, Le KT, Hershman JM. Clinical Review: Hashimoto's thyroiditis and papillary thyroid carcinoma: is there a correlation? J Clin Endocrinol Metab 2013;98(02):474-482

3 Ahn D, Heo SJ, Park JH, et al. Clinical relationship between Hashimoto's thyroiditis and papillary thyroid cancer. Acta Oncol 2011;50(08):1228-1234

4 Zhu F, Shen YB, Li FQ, Fang Y, Hu L, Wu YJ. The effects of Hashimoto thyroiditis on lymph node metastases in unifocal and multifocal papillary thyroid carcinoma: A retrospective Chinese cohort study. Medicine (Baltimore) 2016;95(06): e2674

5 Repplinger D, Bargren A, Zhang YW, Adler JT, Haymart M, Chen H. Is Hashimoto's thyroiditis a risk factor for papillary thyroid cancer? J Surg Res 2008;150(01):49-52

6 Dailey ME, Lindsay S, Skahen R. Relation of thyroid neoplasms to Hashimoto disease of the thyroid gland. AMA Arch Surg 1955;70 (02):291-297

7 Lee JH, Kim Y, Choi JW, Kim YS. The association between papillary thyroid carcinoma and histologically proven Hashimoto's thyroiditis: a meta-analysis. Eur J Endocrinol 2013;168(03): 343-349

8 Konturek A, Barczyński M, Nowak W, Wierzchowski W. Risk of lymph node metastases in multifocal papillary thyroid cancer associated with Hashimoto's thyroiditis. Langenbecks Arch Surg 2014;399(02):229-236

9 Cipolla C, Sandonato L, Graceffa G, et al. Hashimoto thyroiditis coexistent with papillary thyroid carcinoma. Am Surg 2005;71 (10):874-878

10 Arif S, Blanes A, Diaz-Cano SJ. Hashimoto's thyroiditis shares features with early papillary thyroid carcinoma. Histopathology 2002;41(04):357-362

11 Royer MC, Zhang H, Fan CY, Kokoska MS. Genetic alterations in papillary thyroid carcinoma and hashimoto thyroiditis: An analysis of hOGG1 loss of heterozygosity. Arch Otolaryngol Head Neck Surg 2010;136(03):240-242

12 Cordioli MI, Cury AN, Nascimento AO, Oliveira AK, Mello M, Saieg MA. Study of the histological profile of papillary thyroid carcinomas associated with Hashimoto's thyroiditis. Arq Bras Endocrinol Metabol 2013;57(06):445-449

13 Azizi G, Keller JM, Lewis M, et al. Association of Hashimoto's thyroiditis with thyroid cancer. Endocr Relat Cancer 2014;21(06): 845-852

14 Latrofa F, Ricci D, Montanelli L, et al. Lymphocytic thyroiditis on histology correlates with serum thyroglobulin autoantibodies in patients with papillary thyroid carcinoma: impact on detection of serum thyroglobulin. J Clin Endocrinol Metab 2012;97(07): 2380-2387

15 Kurukahvecioglu O, Taneri F, Yüksel O, Aydin A, Tezel E, Onuk E. Total thyroidectomy for the treatment of Hashimoto's thyroiditis coexisting with papillary thyroid carcinoma. Adv Ther 2007;24 (03):510-516

16 Bradly DP, Reddy V, Prinz RA, Gattuso P. Incidental papillary carcinoma in patients treated surgically for benign thyroid diseases. Surgery 2009;146(06):1099-1104

17 Nguyen GK, Ginsberg J, Crockford PM, Villanueva RR. Hashimoto's thyroiditis: cytodiagnostic accuracy and pitfalls. Diagn Cytopathol 1997; 16(06):531-536
18 Ravinsky E, Safneck JR. Differentiation of Hashimoto's thyroiditis from thyroid neoplasms in fine needle aspirates. Acta Cytol 1988; 32(06):854-861

19 Kumarasinghe MP, De Silva S. Pitfalls in cytological diagnosis of autoimmune thyroiditis. Pathology 1999;31(01):1-7

20 MacDonald L, Yazdi HM. Fine needle aspiration biopsy of Hashimoto's thyroiditis. Sources of diagnostic error. Acta Cytol 1999;43 (03):400-406

21 Seifman MA, Grodski SF, Bailey M, Yeung MJ, Serpell JW. Surgery in the setting of Hashimoto's thyroiditis. ANZ J Surg 2011;81(78):519-523

22 Singh B, Shaha AR, Trivedi H, Carew JF, Poluri A, Shah JP. Coexistent Hashimoto's thyroiditis with papillary thyroid carcinoma: impact on presentation, management, and outcome. Surgery 1999;126 (06):1070-1076, discussion 1076-1077

23 Gul K, Dirikoc A, Kiyak G, et al. The association between thyroid carcinoma and Hashimoto's thyroiditis: the ultrasonographic and histopathologic characteristics of malignant nodules. Thyroid 2010;20(08):873-878

24 Muzza M, Degl'Innocenti D, Colombo C, et al. The tight relationship between papillary thyroid cancer, autoimmunity and inflammation: clinical and molecular studies. Clin Endocrinol (Oxf) 2010;72(05):702-708

25 Matsubayashi S, Kawai K, Matsumoto Y, et al. The correlation between papillary thyroid carcinoma and lymphocytic infiltration in the thyroid gland. J Clin Endocrinol Metab 1995;80(12): 3421-3424

26 Gupta S, Patel A, Folstad A, et al. Infiltration of differentiated thyroid carcinoma by proliferating lymphocytes is associated with improved disease-free survival for children and young adults. J Clin Endocrinol Metab 2001;86(03):1346-1354

27 Del Rio P, Cataldo S, Sommaruga L, Concione L, Arcuri MF, Sianesi M. The association between papillary carcinoma and chronic lymphocytic thyroiditis: does it modify the prognosis of cancer? Minerva Endocrinol 2008;33(01):1-5

28 Wang F, Yu X, Shen X, et al. The prognostic value of tumor multifocality in clinical outcomes of papillary thyroid cancer. J Clin Endocrinol Metab 2017;102(09):3241-3250

29 Kiriakopoulos A, Petralias A, Linos D. Multifocal versus solitary papillary thyroid carcinoma. World J Surg 2016;40(09): 2139-2143

30 Kim KJ, Kim SM, Lee YS, Chung WY, Chang HS, Park CS. Prognostic significance of tumor multifocality in papillary thyroid carcinoma and its relationship with primary tumor size: a retrospective study of 2,309 consecutive patients. Ann Surg Oncol 2015;22(01): 125-131

31 Leboulleux S, Rubino C, Baudin E, et al. Prognostic factors for persistent or recurrent disease of papillary thyroid carcinoma with neck lymph node metastases and/or tumor extension beyond the thyroid capsule at initial diagnosis. J Clin Endocrinol Metab 2005;90(10):5723-5729

32 Ross DS, Litofsky D, Ain KB, et al. Recurrence after treatment of micropapillary thyroid cancer. Thyroid 2009;19(10):10431048

33 Neuhold N, Schultheis A, Hermann M, Krotla G, Koperek O, Birner P. Incidental papillary microcarcinoma of the thyroid-further evidence of a very low malignant potential: a retrospective clinicopathological study with up to 30 years of follow-up. Ann Surg Oncol 2011;18(12):3430-3436

34 Zhao Q Ming J, Liu C, et al. Multifocality and total tumor diameter predict central neck lymph node metastases in papillary thyroid microcarcinoma. Ann Surg Oncol 2013;20(03):746-752

35 Vasileiadis I, Karakostas E, Charitoudis G, et al. Papillary thyroid microcarcinoma: clinicopathological characteristics and implications for treatment in 276 patients. Eur J Clin Invest 2012;42(06): 657-664 
36 He Q Zhuang D, Zheng L, et al. The surgical management of papillary thyroid microcarcinoma: a 162-month single-center experience of 273 cases. Am Surg 2012;78(11):1215-1218

37 Kim HJ, Sohn SY, Jang HW, Kim SW, Chung JH. Multifocality, but not bilaterality, is a predictor of disease recurrence/persistence of papillary thyroid carcinoma. World J Surg 2013;37(02):376-384

38 Lin JD, Chao TC, Hsueh C, Kuo SF. High recurrent rate of multicentric papillary thyroid carcinoma. Ann Surg Oncol 2009;16(09): 2609-2616
39 Hay ID, Hutchinson ME, Gonzalez-Losada T, et al. Papillary thyroid microcarcinoma: a study of 900 cases observed in a 60 -year period. Surgery 2008;144(06):980-987, discussion 987-988

40 So YK, Son YI, Hong SD, et al. Subclinical lymph node metastasis in papillary thyroid microcarcinoma: a study of 551 resections. Surgery 2010;148(03):526-531

41 Ito Y, Miyauchi A. Lateral lymph node dissection guided by preoperative and intraoperative findings in differentiated thyroid carcinoma. World J Surg 2008;32(05):729-739 